\title{
Handwashing effect on diarrheal incidence in children under 5 years old in rural eastern Ethiopia: a cluster randomized controlled trial
}

\author{
Ephrem Tefera Solomon ${ }^{1,2^{*}}$, Sirak Robele Gari ${ }^{1}$, Helmut Kloos ${ }^{3}$ and Bezatu Mengistie Alemu ${ }^{2}$
}

\begin{abstract}
Background: Handwashing with soap reduces diarrheal diseases burden considerably. However, the importance of handwashing in homes has received little attention in rural eastern Ethiopia. The effectiveness of handwashing may be reduced by lack of information on when and in what event hands must be washed, the frequency of handwashing, the individual who should wash his/her hands, and the procedure of handwashing. In these areas, indicators of adherence to handwashing are yet to be established. This study aimed at assessing the efficiency of handwashing on reducing diarrheal disease in children under 5 years old in rural kebeles of Dire Dawa, east Ethiopia.

Methods: Community-based cluster randomized controlled trial was conducted in rural kebeles of Dire Dawa for 4 months starting from October 2018 to January 2019. Selected clusters were randomized in intervention and control arms using draw method and data collectors conducted the baseline survey. Households assigned to the intervention group were given two bars of plain soap on a bi-monthly basis together with information promoting hand hygiene. Control households were allowed to continue their habitual handwashing practices. We compared the diarrheal incidences of the intervention and non-intervention households. Generalized estimation equations using Poisson family and log choice of the link was employed to calculate adjusted incidence rate ratio with its 95\% confidence interval.
\end{abstract}

Results: We recorded a significant lesser diarrheal incidence in the handwashing arm than in the non-intervention arm (6.9 versus 13.8 episodes per 100 person weeks of observation). In all, there was a $41 \%$ reduction in diarrheal incidence in the intervention arm in relation to the non-intervention arm.

Conclusion: Handwashing with soap complemented with hand hygiene promotion significantly decreased diarrheal episodes in children under 5 years old in rural kebeles of Dire Dawa. We recommend the promotion and adaptation of washing hands using soap at recommended times to be an effective means of reducing childhood diarrhea morbidity in rural populations of Ethiopia towards achieving the Sustainable Development Goal 6.

Trial registration: PACTR, PACTR201807815961394. Registered 16 July 2018,

Keywords: Handwashing compliance, Under-five children, Childhood diarrhea, Ethiopia

\footnotetext{
* Correspondence: ephtesol@gmail.com

'Ethiopian Institute of Water Resources, Addis Ababa University, Addis Ababa, Ethiopia

${ }^{2}$ College of Health and Medical Sciences, Haramaya University, Harar, Ethiopia

Full list of author information is available at the end of the article
}

(c) The Author(s). 2021 Open Access This article is licensed under a Creative Commons Attribution 4.0 International License, which permits use, sharing, adaptation, distribution and reproduction in any medium or format, as long as you give appropriate credit to the original author(s) and the source, provide a link to the Creative Commons licence, and indicate if changes were made. The images or other third party material in this article are included in the article's Creative Commons licence, unless indicated otherwise in a credit line to the material. If material is not included in the article's Creative Commons licence and your intended use is not permitted by statutory regulation or exceeds the permitted use, you will need to obtain permission directly from the copyright holder. To view a copy of this licence, visit http://creativecommons.org/licenses/by/4.0/. 


\section{Background}

Diarrhea is a severe worldwide health problem, predominantly in LMICs (low-income and middle-income countries) [1]. It was a primary killer of children, responsible for nearly $8 \%$ of the entire deaths in children under 5 years old worldwide in the year 2017 [2]. The United Nations set out 17 SDG (Sustainable Development Goals), the sixth one of which aims to avail water and sanitation to all people in the world by 2030 [3].

Handwashing after contact with excreta is poorly practiced globally, despite the likely positive health benefits. The global mean prevalence of handwashing was estimated at $19 \%$ [4], and it is estimated that inadequate hand hygiene results in nearly 300,000 deaths annually, with the majority of deaths being among children younger than 5 years old [5]. Despite the fact that proper handwashing with soap can reduce the risk of diarrhea by $42-48 \%$ [6], diarrheal pathogens are transmitted by the fecal-oral route [7]. In Ethiopia, the prevalence of diarrhea among under-five children was $12.1 \%$ in 2016 [8]. Some of the risk factors of diarrheal morbidity in children under the age of 5 years in Ethiopia were as follows: sex of the child, the number of under-five children, household economic status, the presence of feces around the pit-hole, and absence of refuse disposal facilities $[9,10]$. Therefore, improved handwashing methods play key role on reducing diarrheal incidence [11]. Specifically, handwashing after defecating and touching feces, before preparation of food and before intake of food may minimize diarrhea risk [1]. Washing hands with plain soap is effective in eliminating pathogenic microorganisms [12].

The diseases burden related to inadequate WASH are avertable with confirmed, cost-effective interventions [13]. A recently updated meta-analysis found large potential reductions in the risk of diarrheal disease through interventions aimed at improving in drinking water, sanitation, and hygiene [14]. Several studies reported that handwashing with soap produced between 25 and $53 \%$ reduction of diarrheal incidence and prevalence in children under 5 years old [11, 15-19]. Characteristics that were independently significantly associated with handwashing were being an adult caregiver, mother's education above primary level, educational level of household heads, ethnicity of the household head, household wealth index, having water available at the place to wash hands after toileting, improved water sources, having soap available at the place to wash hands after toileting, and access to improved sanitation facilities [20-22].

Interventions that improve the obtainability of water with soap at a designated handwashing places are expected to improve handwashing behavior [23] and thus generate broad public health benefits. However, changing handwashing habits is often difficult. In eastern Ethiopia, Jigjiga District, an interventional study on the effect of handwashing on diarrhea of under-fives was carried out by Hashi and colleagues on 1224 under-five children with measurement of compliance with the intervention using drinking water quality test [19]. However, in our study, compliance was measured using surrogate measure (soap wrappers collection) in addition to water quality test. Additionally, in the study area of rural eastern Ethiopia, the importance of handwashing in homes has received little attention, and specific aspects of handwashing such as in what event and when hands must be washed, the frequency of handwashing, the individual who should wash his/her hands, and the procedure of handwashing, are yet to be addressed. Furthermore, indicators of adherence to handwashing are yet to be established. This study aimed at assessing the efficiency of handwashing on reducing diarrheal disease in children under 5 years old in rural kebeles of Dire Dawa, east Ethiopia.

\section{Methods}

\section{Study area and period}

Dire Dawa Administration is located in the eastern Ethiopia at about $500 \mathrm{~km}$ east of Addis Ababa. This small region is administratively divided into nine urban and 38 rural peasant associations in four operational wereda (Wereda are the third-level administrative division of Ethiopia below Region and Zone). As per the report by Water, Mine and Energy Bureau of Dire Dawa, potable water in the rural kebeles were provided by wells and springs. Health services are being delivered to the rural kebeles by seven health centers and 33 health posts (Dire Dawa administration Regional Health Bureau: 2017 six months report (unpublished)). This cluster randomized controlled trial was conducted in rural kebeles of Dire Dawa from October 2018 to January 2019.

\section{Inclusion criteria}

In our study, the included households need to have a minimum of one child under 5 years old and the child should not suffer from chronic illness.

\section{Exclusion criteria}

The excluded households were as follows: those households with mothers/caregivers who were incapable of responding to the questionnaire due to severe illness and households with children under 5 years old who were suffering from persistent diarrhea (three and more unformed stools in a day persisting for greater than 14 days).

\section{Baseline survey and follow-up}

The baseline survey was conducted using a structured and pre-tested questionnaire addressing pertinent 
behavioral, environmental, and socio-demographic factors as well as diarrheal prevalence in a couple of weeks prior to the survey. Afaan Oromo, the local language, was used for the interview. The questionnaire was administered by trained data collectors to mothers or caregivers of under-five children. After completing the baseline survey, data on the occurrence of diarrhea were collected [24] once every 2 weeks by the data collectors. A total of eight rounds of diarrheal occurrences were recorded using pre-structured follow-up visit forms.

\section{Procedure and design of the study}

A cluster randomized controlled trial was carried out to assess the efficiency of handwashing of mothers/caregivers on reducing diarrheal diseases in children under 5 years old in rural kebeles of Dire Dawa from October 2018 to January 2019. The trial was begun the first week of October 2018 and completed in the last week of January 2019. Our rationale for randomizing at the cluster level other than the participant level was to avoid information contamination, so that individuals within a cluster are probably parallel and show comparable results [25]. The rural kebeles of Dire Dawa have four operational wereda or districts having 38 kebeles in total. Administratively, kebele will be divided to sub-kebeles. We randomly selected two districts from the total of four. Then, out of 12 kebeles in the two districts, two kebeles were selected based on their location which was five kilometers far apart in order to avoid information contamination. Twenty four clusters were found in the two kebeles out of which eight clusters were randomly selected for the trial. Four clusters were intervention arm and other four clusters the control arm (Fig. 1).

Diarrheal incidence was calculated as the ratio of counts of new cases of diarrhea by person weeks of observation [26]. We undertook eight series of interviews once every 2 weeks to determine the number of episodes of diarrhea for 16 weeks.

The principal investigator, in collaboration with the study team, arranged gathering with leaders of the community to allocate the clusters in intervention group (IG) and control group (CG). A unique identifier was given to each cluster and papers with identifiers were placed in a pot after folding them. Two collections of pieces of papers equal in number, labeled "IG" and "CG" were folded and placed in another pot. Two anonymous persons from the gathering who had not participated in labeling took one paper from the two pots in the presence of the community leaders and the two papers were paired. This process continued until all papers were paired. Unique identifiers paired with "IG" were allocated to the intervention arm and the others paired with "CG" were allocated to control arm.
Randomization of participants at cluster level is frequently promoted to reduce "contamination" of treatment among intervention and control arms [27]. After getting informed and written consent from every household, data collectors administered a baseline survey to the participants. Lastly, two bars of plain soap were distributed bi-monthly to all intervention households until the end of the study. In each 2-week round, soap was distributed on the first day of the first week starting on Monday, 8 October 2018 (Fig. 1).

\section{Sample size for under-five children and sample size determination for clusters}

The sample size was calculated by taking $35 \%$ reduction in incidence of diarrhea [19] in the intervention arm when compared with the control arm. The following parameters were taken into consideration: $80 \%$ of power, $5 \%$ of significance level, $95 \%$ of confidence level, $10 \%$ for the possibility of refusal by the participants, and design effect with four folds as a result of clustering. These considerations generated 204 children in each arm and a total of 408 children for the study. The required number of clusters was calculated by the method established by Hayes and Bennett [28]. Accordingly, the intervention arm used four clusters and the control arm used four clusters.

\section{Study variables}

The dependent variable was the occurrence of childhood diarrhea every 2 weeks. Child sex and age, number of under-five children per household, history of breastfeeding, family size, mother/caregiver age, availability of plain soap in the home, handwashing before food preparation, before intake of food, before feeding under-five children, after use of toilet, after contact with child feces, presence of refuse disposal facility, drinking water storage container, presence of watch in the house, presence of television in the house, mother's education, availability of latrine, the household water source, time taken to fetch water for a round trip, and microbial water quality were the independent variables.

\section{Intervention}

Mothers/caregivers of the intervention households were provided with two bars of plain soap. Information about hand hygiene for washing hands in the following five recommended times: before food preparation, before food intake, before feeding under-five child, after toilet use, and after cleaning the child's bottom was given. Participants were instructed to keep the soap wrappers. The intervention providers collected the soap wrappers on a bi-monthly basis before giving each participant the next two bars of soap; the wrappers served as a measure of the study population's adherence to the intervention. In 


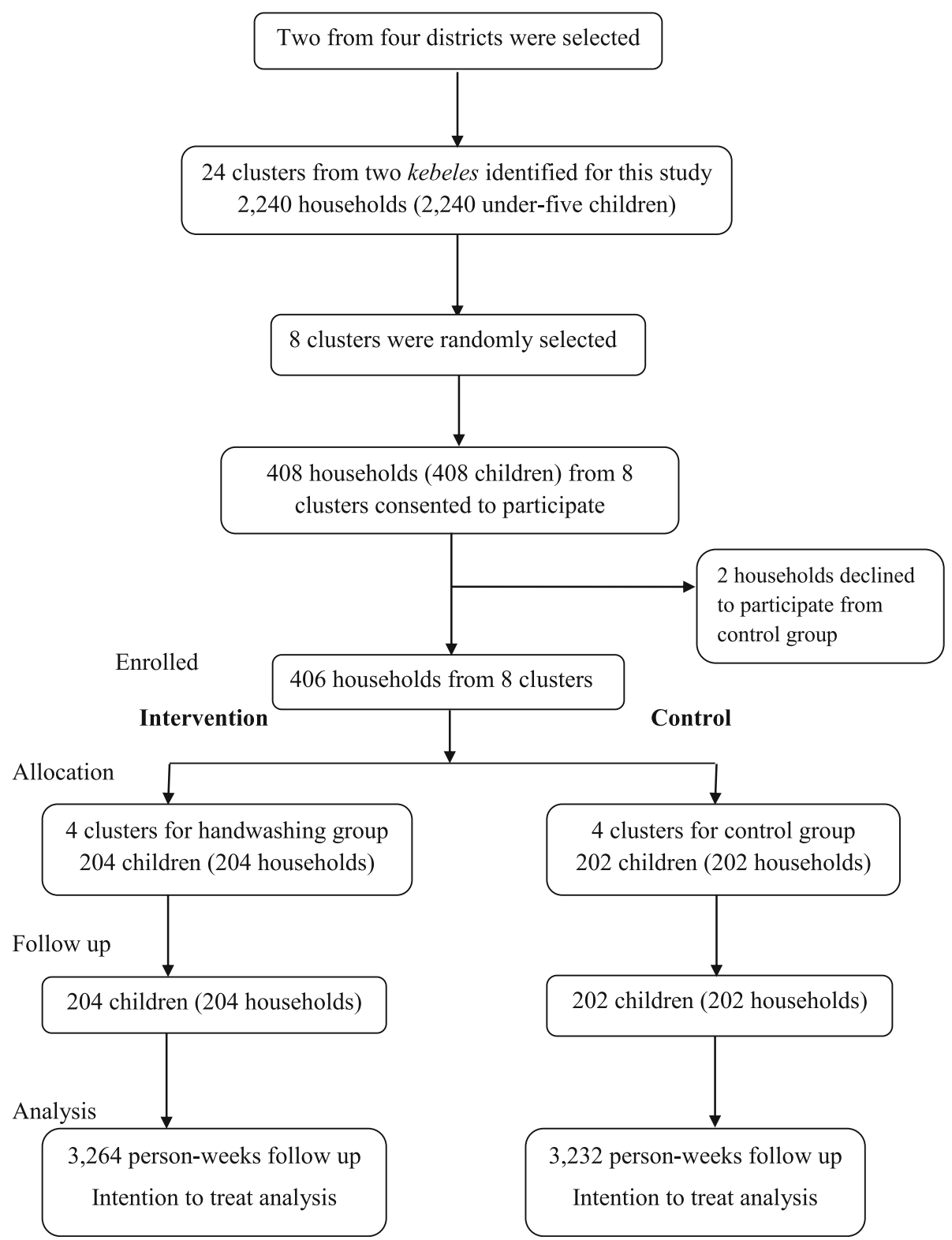

Fig. 1 Selection and follow-up flow of study participants for the community randomized controlled trial, rural Dire Dawa, eastern Ethiopia, 2019

each household, the intervention providers delivered a lesson on handwashing and demonstrated hand hygiene following recommendations of CDC [29]. Intervention providers received training on hand hygiene from the principal investigator. The guidelines are as follows: wet hands with water, lather hands completely with plain soap, rub hands for one third of a minute, wash using water, and dry [29].

Every time the intervention providers visited the intervention households, they reminded the mother/caregiver of hand hygiene once every 2 weeks. Moreover, the intervention providers were in close contact with the principal investigator, who reminded them of soap delivery. Mothers and caregivers in the intervention households including under-five children who were old enough to obey orders were encouraged by the intervention providers to practice handwashing at five critical times. The intervention providers did not encourage water treatment and other protective actions that can possibly lessen the occurrence of diarrhea. Handwashing at critical times was the only intervention mentioned.

Control households were allowed to continue their habitual handwashing practices. They were neither encouraged nor discouraged to practice handwashing with soap 
and water. However, data collectors visited each household in the control group on a bi-monthly basis to record occurrence of diarrhea in children under 5 years old.

\section{Operational definition of terms}

Caregiver: Someone who takes care of an under-five child in the absence of the biological mother.

Control arm: Clusters that were not given plain soap and were allowed continuing their habitual handwashing practices.

Diarrhea: More frequent passage of loose stools than is normal for the individual, which is three times and more within $24 \mathrm{~h}$ [24].

Effect: The association of washing hands with plain soap at recommended times and the diarrheal incidence in children under 5 years old.

Family size: Total number of individuals living in a given household at the time of the survey.

Hand hygiene promotion: Educating mothers, guardians, and caregivers to wash their own hands and their children under 5 years old with plain soap at recommended times.

Handwashing group: Clusters supplied with plain soap for washing hands with soap at recommended times.

Handwashing: Involves the five steps of handwashing: wet with water; lather completely with soap, scrub the hands for one third of a minute, wash using water, and dry [29].

Household head: Mother or father who generates income for the family's living expenses.

Improved water: Water gotten from public tap, pipe, protected well, protected spring, or rainwater collection

Kebele: Is the smallest administrative unit of Ethiopia.

Persistent diarrhea: The abrupt onset of three and more unformed stools in a day persisting for greater than 14 days [30].

Plain soap: A soap containing no triclocarban (1.2\%) as an antibacterial agent.

Under-five children: Children of age range 6 to 59 months during the survey period.

Unimproved water: Water gotten from unprotected springs, unprotected dug wells, rivers, or streams.

\section{Data collection}

At baseline, data were collected through a structured questionnaire. The questionnaire was first written in English, translated to Oromiffa, and back translated to English to ensure reliability of the Oromiffa translation. Data collection was carried out using the Oromiffa version by data collectors, intervention providers, and supervisors. The data collectors and intervention providers were grade 10 completed students wherein the supervisors were high school graduates. The field workers were recruited from the local areas and trained on proper data collection by the principal investigator within 2 days. At the end of the training, the data collection tool was pilot tested on $5 \%$ of the sample size in a neighboring kebele which was not included in the study conducted later. Based on the results of the pilot testing, the data collection tool was improved.

In this study, the main outcome variable was childhood diarrhea. In each 2-week round, an episode of diarrhea was counted as a new if the under-five child did not pass loose stools for 3 days [31]. The data collectors asked the mothers/caregivers when the diarrhea started and when it ended during each round of data collection; they also informed the mothers/caregivers either to remember carefully the date or to take notes about the date. Information was gathered by the data collectors on occurrence of diarrhea, handwashing practices, and the collection of soap wrapper on a bi-monthly basis for 16 weeks during the eight rounds.

The secondary outcome variable of this trial was compliance with the intervention by participating households. Compliance was measured by the number of soap wrappers collected; this measure was used as an indicator of soap use. The intervention households were also told to use the soap for bathing and washing dishes as well as washing clothes, because they were given $200 \mathrm{gm}$ bar of soap per week (two bars of soap for each 2-week round).

Random water samples were taken from $10 \%$ households of the intervention and control arms at baseline and end line of the study for microbiological water quality test. A $1 \%$ sodium thiosulfate was added in water samples to neutralize chlorine. The collected water samples kept in ice box were brought to the laboratory of Water Supply and Sewerage Authority within $4 \mathrm{~h}$ of being collected. The collected water samples were processed and examined by the membrane filtration technique to detect and quantify Escherichia coli, and this was performed by the Laboratory Technician in Dire Dawa Water Supply Sewerage Authority. Using the membrane filter technique, sample was passed through the membrane using a filter funnel and vacuum system. Any organisms in the sample are concentrated on the surface of the membrane. The membrane, with its trapped bacteria, is then placed in a special plate containing a pad saturated with lactose broth. The passage of nutrients through the filter during incubation facilitates the growth of organisms in the form of colonies, on the upper surface of the membrane that will be counted after $24 \mathrm{~h}$ of $44^{\circ} \mathrm{C}$ incubation [32].

We tested the microbial quality of drinking water from both arms to assess indirectly any changes due to the intervention, especially for the intervention households. Continual handwashing decreases the chances of contamination of household- stored water and thus the risk 
of diarrhea. E. coli was considered as the reliable of all indicators of fecal contamination [33].

\section{Data analysis}

Data were analyzed with STATA 15.0 after importing them from EPI-Data 3.1. Diarrheal incidence was compared between intervention and control arms by intention-to-treat analysis. Data of the intervention and non-intervention arms were paralleled at the baseline and during the follow-up period. Crude and adjusted incidence rate ratio with the accompanying 95\% confidence intervals were calculated by generalized estimation equations (GEE) with Poisson family and log choice of the link after adjusting for potential confounders [34].

We used GEE instead of zero-inflated Poisson regression just for modeling longitudinal data. The GEE method is usually employed when the interest is to see the effect of population-averaged of factors on the outcomes of interest [35]. When the zero counts are in excess of the other counts, zero-inflated Poisson regression will be recommended. In our dataset, diarrhea counts are expressed in terms of presence or absence; that is why we did not use the zero-inflated model.

\section{Results}

In the present study, 406 of the 408 (99.5\%) selected households agreed to participate. Of these, 204 households in interventional arm and 202 households in nonintervention arm completed the entire 16 weeks of follow-up.

Median age of the mothers/caregivers was 28 (IQR 25-30) years and median age of children under 5 years old was 36 (IQR 24-48) months. The number of households per cluster was 51. Intervention and nonintervention arms were equivalent with regard to most of the measured variables (Table 1).

Intervention and non-intervention households had comparable features at the baseline; they were comparable in sex of the children, availability of plain soap in the home, and reported similar behavior of handwashing before preparing food, before eating food and after use of toilet. They also had similar numbers of refuse disposal facilities and similar household water storage containers and socio-economic status. The 2-week prevalence of diarrhea at the pre-intervention phase was $24.26 \%$ in those who were not covered by the intervention and $25.49 \%$ in those who were covered by the intervention (Table 1). The participants experienced no harm as a result of the intervention.

The prevalence of diarrhea at baseline was 24.9\% whereas it was $17.7 \%$ at the end line of the study time thereby showing the effectiveness of the intervention. Similarly, microbial water quality test at baseline showed
Table 1 Socio-demographic, behavioral, and environmental variables and pre-intervention diarrhea of control and intervention groups at baseline, rural kebeles of Dire Dawa, 2019

\begin{tabular}{|c|c|c|}
\hline Factors & Control arm & Intervention arm \\
\hline Number of clusters & 4 & 4 \\
\hline Number of participating households & 202 & 204 \\
\hline Number children under five years old & 202 & 204 \\
\hline Mean number of household members per household & 5.76 & 5.09 \\
\hline Median age children under five years old in months & 38 (IQR: 32-48) & 28 (IQR: 22.5-38.5) \\
\hline Median age of mother in years & 28 (IQR: $25-30)$ & 28 (IQR: 25-30.5) \\
\hline \multicolumn{3}{|l|}{ Sex of the child } \\
\hline Male & $101(50.00)$ & $104(51.23)$ \\
\hline Female & $101(50.00)$ & $99(48.77)$ \\
\hline \multicolumn{3}{|l|}{ Mother's education } \\
\hline Unable to read and write & $176(87.13)$ & $164(80.39)$ \\
\hline Primary and above & $26(12.87)$ & $40(19.61)$ \\
\hline \multicolumn{3}{|l|}{ Father's education } \\
\hline Unable to read and write & $159(78.71)$ & $107(52.45)$ \\
\hline Primary and above & $43(21.29)$ & $97(47.55)$ \\
\hline \multicolumn{3}{|l|}{ Toilet ownership } \\
\hline No & $170(84.16)$ & $154(75.49)$ \\
\hline Yes & $32(15.84)$ & $50(24.51)$ \\
\hline \multicolumn{3}{|l|}{ Soap present } \\
\hline No & $160(79.21)$ & $163(79.90)$ \\
\hline Yes & $42(20.79)$ & $41(20.10)$ \\
\hline \multicolumn{3}{|l|}{ Handwashing before preparing food } \\
\hline No & $185(91.58)$ & $177(86.76)$ \\
\hline Yes & $17(8.42)$ & $27(13.24)$ \\
\hline \multicolumn{3}{|l|}{ Handwashing before eating food } \\
\hline No & $175(86.63)$ & $181(88.73)$ \\
\hline Yes & $27(13.37)$ & $23(11.27)$ \\
\hline \multicolumn{3}{|l|}{\begin{tabular}{|l} 
Handwashing before feeding under-five child \\
\end{tabular}} \\
\hline No & $156(77.23)$ & $179(87.75)$ \\
\hline Yes & $46(22.77)$ & $25(12.25)$ \\
\hline \multicolumn{3}{|l|}{ Handwashing after use of toilet } \\
\hline No & $176(87.13)$ & $173(84.80)$ \\
\hline Yes & $26(12.87)$ & $31(15.20)$ \\
\hline \multicolumn{3}{|l|}{ Handwashing after contact with child feces } \\
\hline No & $178(88.12)$ & $162(79.41)$ \\
\hline Yes & $24(11.88)$ & $42(20.59)$ \\
\hline \multicolumn{3}{|l|}{\begin{tabular}{|l} 
Refuse disposal facility available \\
\end{tabular}} \\
\hline No & $162(80.20)$ & $167(81.86)$ \\
\hline Yes & $40(19.80)$ & $37(18.14)$ \\
\hline \multicolumn{3}{|l|}{ Water source } \\
\hline Unimproved & $6(2.97)$ & $78(38.24)$ \\
\hline Improved & $196(97.03)$ & $126(61.76)$ \\
\hline \multicolumn{3}{|l|}{ Time taken to fetch water for a round trip } \\
\hline Less than or equal to half an hour & $140(69.31)$ & $71(34.80)$ \\
\hline More than half an hour & $62(30.69)$ & $133(65.20)$ \\
\hline \multicolumn{3}{|l|}{ Water storage container } \\
\hline Wide mouth & $44(21.78)$ & $37(18.14)$ \\
\hline Narrow mouth & $158(78.22)$ & $167(81.86)$ \\
\hline \multicolumn{3}{|l|}{ Own watch } \\
\hline No & $185(91.58)$ & $175(85.78)$ \\
\hline Yes & $17(8.42)$ & $29(14.22)$ \\
\hline \multicolumn{3}{|l|}{ Own television } \\
\hline No & $191(94.55)$ & $194(95.10)$ \\
\hline Yes & $11(5.45)$ & $10(4.90)$ \\
\hline \multicolumn{3}{|l|}{ Diarrhea prevalence in the 2-weeks prior to the survey } \\
\hline No & $153(75.74)$ & $152(74.51)$ \\
\hline Yes & $49(24.26)$ & $52(25.49)$ \\
\hline
\end{tabular}

IQR: Interquartile range 


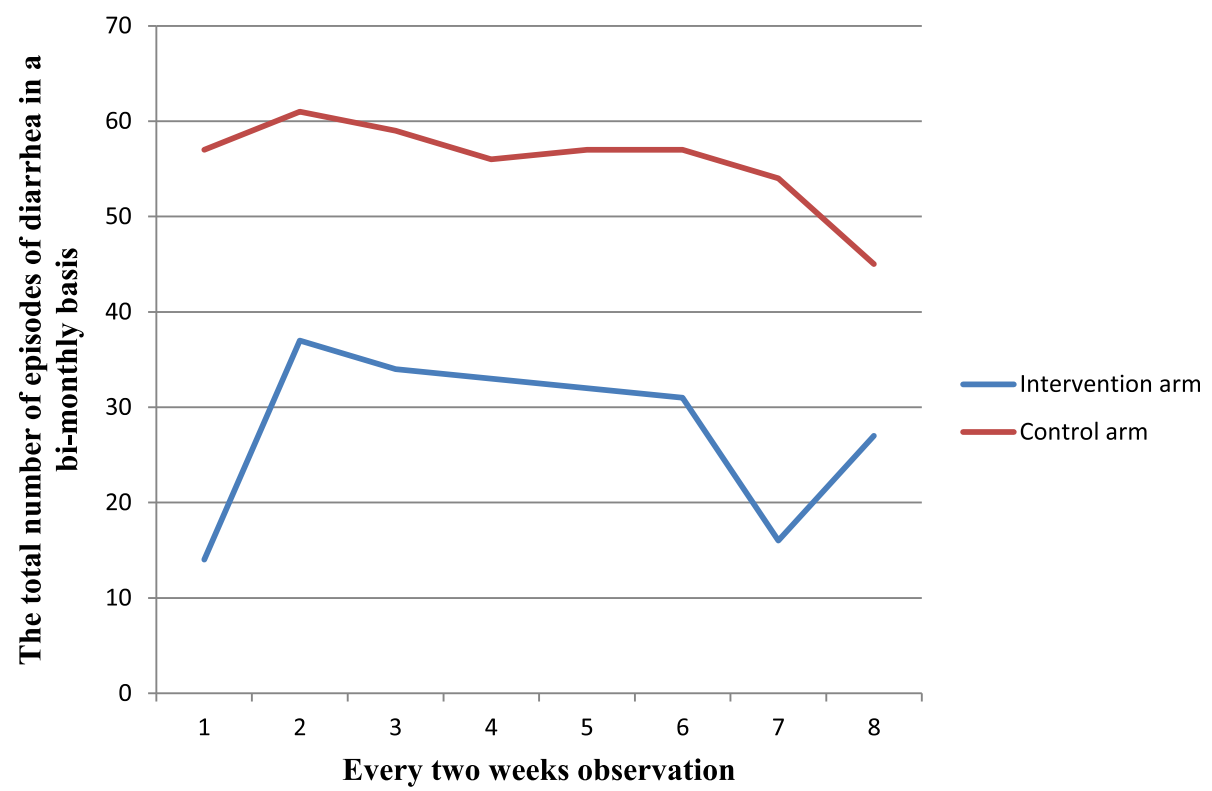

Fig. 2 Total number of episodes of diarrhea recorded at 2-week observations for intervention and control groups in rural Dire Dawa, eastern Ethiopia, 2019

Table 2 Effect of handwashing on diarrheal incidence in children under 5 years old as analyzed by multivariable analysis in rural kebeles of Dire Dawa, east Ethiopia, 2019

\begin{tabular}{|c|c|c|c|}
\hline Features & Crude IRR CI (95\%) & Adjusted IRR CI (95\%) & $p$ value \\
\hline Interventional arm & $0.59(0.53-0.65)$ & $0.59(0.53-0.65)$ & $<0.001$ \\
\hline Non-intervention arm & 1 & 1 & \\
\hline Age of the child & $1.00(0.99-1.00)$ & $1.00(0.99-1.00)$ & 0.991 \\
\hline \multicolumn{4}{|l|}{ Sex of the child } \\
\hline Female & $0.99(0.92-1.08)$ & $0.99(0.92-1.08)$ & 0.947 \\
\hline Male & 1 & 1 & \\
\hline \multicolumn{4}{|l|}{ History of breastfeeding } \\
\hline Yes & $1.02(0.81-1.27)$ & $1.02(0.81-1.27)$ & 0.872 \\
\hline No & 1 & 1 & \\
\hline Number of household members & $1.00(0.98-1.02)$ & $1.00(0.98-1.02)$ & 0.807 \\
\hline \multicolumn{4}{|l|}{ Refuse disposal facility present } \\
\hline Yes & $1.01(0.91-1.11)$ & $1.01(0.91-1.12)$ & 0.907 \\
\hline No & 1 & 1 & \\
\hline \multicolumn{4}{|l|}{ Latrine present } \\
\hline Yes & $0.99(0.91-1.10)$ & $0.99(0.90-1.09)$ & 0.856 \\
\hline No & 1 & 1 & \\
\hline \multicolumn{4}{|c|}{ Drinking water source for the household } \\
\hline Improved source & $0.99(0.91-1.08)$ & $0.99(0.91-1.07)$ & 0.792 \\
\hline Unimproved source & 1 & 1 & \\
\hline \multicolumn{4}{|l|}{ Water storage container } \\
\hline Narrow necked & $0.98(0.89-1.09)$ & $0.98(0.88-1.09)$ & 0.717 \\
\hline Wide necked & 1 & 1 & \\
\hline
\end{tabular}

IRR incidence rate ratio, $\mathrm{Cl}$ confidence interval; the statistical test used is GEE 
Table 3 Days gone with diarrhea against study arms in children under 5 year old, rural kebeles of Dire Dawa, east Ethiopia, 2019

\begin{tabular}{lllll}
\hline Arms & No of diarrheal episodes & No of under-five children & Total days of observation & \% of days with diarrhea \\
\hline Handwashing arm & 224 & 204 & 22,440 & 1.00 \\
Control arm & 446 & 202 & 22,220 & 2.01
\end{tabular}

No number

that $80.95 \%$ of the water samples tested was contaminated with $E$. coli at baseline; however, $47.62 \%$ was contaminated with $E$. coli at the end line of the study in the intervention households.

\section{Diarrheal incidence}

Four hundred forty-six diarrheal episodes were recorded in the control arm (13.8 episodes per 100 person weeks of observation), and 224 diarrheal episodes were recorded in the intervention arm (6.9 episodes per 100 person weeks of observation). Episode numbers of diarrhea on a bi-monthly basis against weeks of observation are shown in Fig. 2.

Having controlled for sex of the child, history of breastfeeding, number of household members, refuse disposal facility, availability of latrine, drinking water source, and household water storage container, reduced diarrhea risk was recorded in under-five children in the interventional arm ([adjusted incidence rate ratio] aIRR $=0.59, C I$ [95\%] 0.53-0.65). An overall reduction of $41 \%$ in diarrheal incidence was observed in children under 5 years old in the intervention arm than those in the nonintervention arm (Table 2).

During the 16 weeks of observation, the diarrhea experience of under-five children in households of the interventional arm was $1 \%$ of 22,440 study days, wherein the diarrhea experience of the children in the nonintervention households was $2.01 \%$ of 22,220 study days (Table 3).

In the intervention, households' handwashing practices exhibited different effects on reducing episodes of diarrheal disease among the various ranges of age in children under 5 years old. Higher effect $(52 \%)$ was observed in children aged 1 to 2 years (Table 4).

\section{Household microbial water quality}

At baseline, $80.95 \%$ and $80.0 \%$ of the sampled water from the intervention and control arms, respectively, were contaminated with $E$. coli and with no significant difference in counts $(p=0.311)$. After the intervention, significantly fewer samples from the intervention (47.62\%) households than from the control households $(85.0 \%)$ were contaminated $(p=0.033)$ (Table 5).

\section{Compliance with the intervention}

Intervention providers collected $78.24 \%$ of the total number of soap wrappers distributed during the entire 16-week intervention.

With regard to drinking water treatment at baseline, 14 households (6.9\%) in the intervention arm and 8 households $(4.0 \%)$ in non-intervention arm treated the drinking water by various methods.

\section{Discussion}

In this study, we assessed the efficiency of household handwashing on reduction of diarrheal diseases in children under 5 years old in rural kebeles of Dire Dawa. Handwashing with soap produced a $41.0 \%$ of reduction of diarrheal incidence in children under 5 years old in the interventional households than in the nonintervention households ( $\mathrm{aIRR}=0.59, \mathrm{CI}$ [95\%] 0.530.65). Additionally, for children who had episodes of diarrhea, the number of days with diarrhea in the intervention arm was half the number of days for those in the control arm.

The $41 \%$ reduction of diarrheal incidence of this study was lower than the 56\% reduction reported in 2-5 year old children in a peri-urban slum of Dhaka City, Bangladesh, during a 1-year surveillance [36] and similar

Table 4 Intervention effect among diverse age range of children under 5 years old in rural kebeles of Dire Dawa, east Ethiopia, 2019

\begin{tabular}{|c|c|c|c|c|c|c|c|}
\hline \multirow[t]{2}{*}{ Age range } & \multicolumn{3}{|l|}{ Control arm $(n=202)$} & \multicolumn{4}{|c|}{ Interventional arm $(n=204)$} \\
\hline & $\begin{array}{l}\text { Counts of diarrheal } \\
\text { episodes }\end{array}$ & PWO & $\begin{array}{l}\text { Incidence of } \\
\text { diarrhea }\end{array}$ & $\begin{array}{l}\text { Counts of diarrheal } \\
\text { episodes }\end{array}$ & PWO & $\begin{array}{l}\text { Incidence of } \\
\text { diarrhea }\end{array}$ & $\begin{array}{l}\text { Reduction in } \\
\%\end{array}$ \\
\hline$<1$ year & 36 & 240 & 15.0 & 47 & 608 & 7.7 & 48.67 \\
\hline $\begin{array}{l}1 \text { to } 2 \\
\text { years }\end{array}$ & 180 & 1328 & 13.6 & 111 & 1712 & 6.5 & 52.21 \\
\hline $\begin{array}{l}3 \text { to } 4 \\
\text { years }\end{array}$ & 230 & 1664 & 13.8 & 66 & 944 & 7.0 & 49.28 \\
\hline
\end{tabular}

Incidence of diarrhea = counts of diarrheal episodes/100 person weeks of observation, PWO = person weeks of observation 
Table 5 Intervention and control households' numbers with E. coli in drinking water at baseline and end line, in rural kebeles of Dire Dawa, east Ethiopia, 2019

\begin{tabular}{llll}
\hline E. coli in drinking water & Intervention households $\boldsymbol{N}(\%)$ & Control households $\boldsymbol{N}(\%)$ & $\boldsymbol{p}$ value \\
\hline Base line & $17(80.95)$ & $16(80.00)$ & 0.311 \\
End of the study time & $10(47.62)$ & $17(85.00)$ & 0.033 \\
\hline
\end{tabular}

$N$ sample size; significance level was set at $p<0.05$

reductions in two trials in Karachi, Pakistan, 53\% and $51 \%$, respectively. It was also lower than the $48 \%$ reduction resulted from the conclusion of a systematic review [37]. The interventions in these studies were carried out for 1 year and 8 months, respectively, with visits once in a week $[38,39]$. The lower reduction achieved in our study may be explained by the shorter study period ( 4 month) than in the above studies. The $41 \%$ reduction attained in the present study is consistent with results of similar studies in Kenya (41\%) [18] and in Karachi, Pakistan (39\%) [11], which also used plain soap. Our study results are also consistent with the conclusion of a recent systematic review that handwashing may decrease diarrheal disease risk by $40 \%$ [4] as well as with the conclusion of systematic review having a reduction in risk of $43 \%$ [40]. On the contrary, it is larger than trials in different countries such as Myanmar (30\%) [15], Malawi (27\%) [16], and India (25\%) [17]. It is also larger than the conclusions of a meta-analysis (31\%), systematic review (27\%), and a recent updated meta-analysis and meta-regression $30 \%[14,41,42]$. The fact that different critical times for handwashing were studied in the Myanmar trial may explain differences with our trial. Furthermore, the high reduction achieved in our study might be explained by greater compliance (78.24\%).

The reduction in the incidence of diarrhea we achieved was by far greater than in studies carried out in a Calcutta slum in India [43] and in the Netherlands [44], both of which reported lack of intervention effectiveness. Moreover, the intervention and control households in the above studies were not comparable in most of their baseline characteristics, whereas they were fairly balanced in our study. These disparities may have contributed to these differences.

The quality of drinking water in water containers was improved after the handwashing intervention. This could be due to improved handwashing practices in the intervention households as clean hands protect the drinking water from being contaminated. This result corroborates a similar trial carried out in Jigjiga District in eastern Ethiopia [19], further indicating that regular handwashing prevents or reduces diarrhea transmission.

Handwashing with soap is not only effective in preventing diarrhea [38] but may also be even more effective in preventing diarrheal diseases than improving water supply and sanitation [45]. Unlike water treatment products, plain soap is easily accessible and affordable. The common price of a bar of soap in Ethiopian in retail shops is 10 Birr (0.31 US\$). Furthermore, handwashing facilities are more manageable and can be constructed with local materials by households, unlike toilets.

This study has two limitations: first, we expected recall bias because we collected information about the occurrence of diarrhea once in a couple of weeks. Managing this limitation was by carefully training the data collectors to repeatedly ask the mothers/caregivers to specify the date when the diarrhea began and when it ended. Second, because the intervention material (bars of plain soap) was given to the participants free of charge, we anticipated that Hawthorne effect and courtesy bias might inflate the intervention effect. In contrast, these biases were decreased by using intervention providers independent of data collectors to distribute bars of soap to participants.

\section{Conclusion}

This study reveals that, handwashing with soap complemented with hand hygiene promotion can significantly reduce diarrheal episodes in children under 5 years old in rural kebeles of Dire Dawa. Therefore, we recommend the promotion and adaptation of handwashing with soap at critical times as an effective, simple, and affordable means of reducing childhood diarrhea morbidity in rural populations of Ethiopia and other developing countries and thus for contributing to attainment of SDG 6 set by the United Nations.

\section{Abbreviations}

CG: Control group; GEE: Generalized estimation equations; IG: Intervention group; IQR: Interquartile range

\section{Supplementary Information}

The online version contains supplementary material available at https://doi. org/10.1186/s41182-021-00315-1.

Additional file 1. Supplement file Questionnaire.

\section{Acknowledgements}

The authors thank Ethiopian Institute of Water Resources for its financial support and the following organizations for providing support in terms of material: Dire Dawa Health Bureau, Shemu Soap, Detergent PLC and Conel Detergent Factory and Dire Dawa Water Supply and Sewerage Authority. We also thank participating households for their willingness and field workers for their engagement in data collection. Staff members of the nearby Health Center and Health post are also acknowledged. Meskerem Alemayehu is also highly appreciated for her immense contribution in this research work. 


\section{Authors' contributions}

ETS, SRG, and BMA conceived the study, drafted the proposal, monitored data collection, and coordinated field work. ETS, SRG, and BMA carried out data analysis and interpretation of the findings and wrote the manuscript. HK edited the manuscript. All authors read and approved the final manuscript.

\section{Funding}

This study received no funding from external sources except from the home university of the principal author

\section{Availability of data and materials}

The authors are willing to share the data on which results and conclusion are based upon request by the journal.

\section{Declarations}

\section{Ethics and consent to participate}

Ethical clearance was obtained from National Research Ethics Review Committee (NRERC) Addis Ababa, Ethiopia. Written informed consent was obtained from mothers/caregivers of under-five children after clarifying them about the objective of the study. Results were kept confidential. Mothers/ caregivers of under-five children with diarrhea were advised to consult the health center or health post of their catchment area. After completion of the study, control households were supplied by plain soaps so as to maintain the beneficence of control households. Moreover, our manuscript reporting adhered to CONSORT guidelines.

\section{Consent for publication}

Not applicable

\section{Competing interests}

No conflict of interests is declared by the authors.

\section{Author details}

${ }^{1}$ Ethiopian Institute of Water Resources, Addis Ababa University, Addis Ababa, Ethiopia. ${ }^{2}$ College of Health and Medical Sciences, Haramaya University, Harar, Ethiopia. ${ }^{3}$ San Francisco Medical Center, University of California, San Francisco, CA, USA.

\section{Received: 15 January 2021 Accepted: 10 March 2021}

Published online: 23 March 2021

\section{References}

1. Ejemot RI, Ehiri JE, Meremikwu MM, Critchley JA. Cochrane review: hand washing for preventing diarrhoea. Evid Based Child Health. 2009;4(2):893939. https://doi.org/10.1002/ebch.373.

2. UNICEF, Diarrhoeal disease. https://data.unicef.org/topic/child-health/dia rrhoeal-disease/ Accessed on 30 December 2019. 2019.

3. World Health Organization. World health statistics 2016: monitoring health for the SDGs sustainable development goals. Geneva: World Health Organization; 2016.

4. Freeman MC, Stocks ME, Cumming O, Jeandron A, Higgins J, et al. Systematic review: hygiene and health: systematic review of handwashing practices worldwide and update of health effects. Tropical Med Int Health. 2014;19(8):906-16. https://doi.org/10.1111/tmi.12339.

5. George CM, Biswas S, Jung D, Perin J, Parvin T, Monira S, Saif-Ur-Rahman KM, Rashid MU, Bhuyian SI, Thomas ED, Dreibelbis R, Begum F, Zohura F, Zhang X, Sack DA, Alam M, Sack RB, Leontsini E, Winch PJ. Psychosocial factors mediating the effect of the $\mathrm{CHoBI}$ intervention on handwashing with soap: A randomized controlled trial. Health Educ Behav. 2017;44(4): 613-25. https://doi.org/10.1177/1090198116683141.

6. Bloomfield SF, Aiello AE, Cookson B, O'boyle C, Larson EL. The effectiveness of hand hygiene procedures in reducing the risks of infections in home and community settings including handwashing and alcohol-based hand sanitizers. Am J Infect Control. 2007;35(10):S27-64. https://doi.org/10.1016/j.a jic.2007.07.001.

7. Keusch GT, Walker CF, Das JK, Horton S, Habte D. Diarrheal diseases. In: Black RE, Laxminarayan R, Temmerman M, Walker N, editors. Reproductive maternal newborn and child health. Disease control priorities. Volume 2. Washington, DC: The World Bank; 2016. p. 163-85.
8. Central Statistical Agency (CSA) [Ethiopia] and ICF International. Ethiopia Demographic and Health Survey 2016. Addis Ababa, Ethiopia, and Rockville, Maryland, USA: CSA and ICF; 2016.

9. Woldu W, Bitew BD, Gizaw Z. Socioeconomic factors associated with diarrheal diseases among under-five children of the nomadic population in northeast Ethiopia. Trop Med Health. 2016;44(1):40. https://doi.org/10.1186/ s41182-016-0040-7.

10. Regassa G, Birke W, Deboch B, Belachew T. Environmental determinants of diarrhea among under-five children in Nekemte Town, western Ethiopia. Ethiop J Health Sci. 2008;18(2). https://www.ajol.info/index.php/ejhs/article/ viewFile/145957/135474.

11. Luby SP, Agboatwalla M, Painter J, Altaf A, Billhimer WL, Hoekstra RM. Effect of intensive handwashing promotion on childhood diarrhea in high-risk communities in Pakistan: a randomized controlled trial. JAMA. 2004;291(21): 2547-54. https://doi.org/10.1001/jama.291.21.2547.

12. Kampf G, Kramer A. Epidemiologic background of hand hygiene and evaluation of the most important agents for scrubs and rubs. Clin Microbiol Rev. 2004;17(4):863-93. https://doi.org/10.1128/CMR.17.4.863-893.2004.

13. Bartram J, Cairncross S. Hygiene, sanitation, and water: forgotten foundations of health. PLOS Med. 2010;7(11):e1000367. https://doi.org/10.13 71/journal.pmed.1000367.

14. Wolf J, Hunter PR, Freeman MC, Cumming O, Clasen T, Bartram J, Higgins JPT, Johnston R, Medlicott K, Boisson S, Prüss-Ustün A. Impact of drinking water, sanitation and handwashing with soap on childhood diarrhoeal disease: updated meta-analysis and meta-regression. Tropical Med Int Health. 2018;23(5):508-25. https://doi.org/10.1111/tmi.13051.

15. Han AM, Hlaing T. Prevention of diarrhoea and dysentery by hand washing. Trans R Soc Trop Med Hyg. 1989;83(1):128-31. https://doi.org/10.1016/00359203(89)90737-2.

16. Peterson FA, Roberts L, Toole MJ, Peterson DE. The effect of soap distribution on diarrhoea: Nyamithuthu Refugee Camp. Int J Epidemiol. 1998;27(3):520-4. https://doi.org/10.1093/ije/27.3.520.

17. Nicholson JA, Naeeni M, Hoptroff M, Matheson JR, Roberts AJ, Taylor D, Sidibe M, Weir AJ, Damle SG, Wright RL. An investigation of the effects of a hand washing intervention on health outcomes and school absence using a randomised trial in Indian urban communities. Tropical Med Int Health. 2014;19(3):284-92. https://doi.org/10.1111/tmi.12254.

18. Kamm K, Feikin D, Bigogo G, Aol G, Audi A, et al. Associations between presence of handwashing stations and soap in the home and diarrhoea and respiratory illness, in children less than five years old in rural western Kenya. Tropical Med Int Health. 2014;19(4):398-406. https://doi.org/10.1111/ tmi.12263.

19. Hashi A, Kumie A, Gasana J. Hand washing with soap and WASH educational intervention reduces under-five childhood diarrhoea incidence in Jigjiga District, Eastern Ethiopia: a community-based cluster randomized controlled trial. Prev Med Rep. 2017;6:361-8. https://doi.org/10.1016/j. pmedr.2017.04.011.

20. Luby SP, Halder AK, Tronchet C, Akhter S, Bhuiya A, et al. Household characteristics associated with handwashing with soap in rural Bangladesh. Am J Trop Med Hyg. 2009;81(5):882-7. https://doi.org/10.4269/ajtmh.2009. 09-0031.

21. To KG, Lee J-K, Nam Y-S, Trinh OTH, Van Do D. Hand washing behavior and associated factors in Vietnam based on the Multiple Indicator Cluster Survey, 2010-2011. Glob Health Action. 2016;9.

22. Schmidt WP, Aunger R, Coombes $Y$, Maina PM, Matiko CN, Biran A, Curtis V. Determinants of handwashing practices in Kenya: the role of media exposure, poverty and infrastructure. Tropical Med Int Health. 2009;14(12): 1534-41. https://doi.org/10.1111/j.1365-3156.2009.02404.x.

23. Luby SP, Agboatwalla M, Bowen A, Kenah E, Sharker $Y$, et al. Difficulties in maintaining improved handwashing behavior, Karachi, Pakistan. Am J Trop Med Hyg. 2009;81(1):140-5. https://doi.org/10.4269/ajtmh.2009.81.140.

24. World Health Organization. Diarrhoeal disease Fact sheet. Accessed on 16 Dec 2019. Geneva: WHO library; 2017.

25. Cook AJ, Delong E, Murray DM, Vollmer WM, Heagerty PJ. Statistical lessons learned for designing cluster randomized pragmatic clinical trials from the $\mathrm{NIH}$ Health Care Systems Collaboratory Biostatistics and Design Core. Clinical Trials. 2016;13(5):504-12. https://doi.org/10.1177/1740774516646578.

26. Schmidt W-P, Arnold BF, Boisson S, Genser B, Luby SP, Barreto ML, Clasen T, Cairncross S. Epidemiological methods in diarrhoea studies — an update. Int J Epidemiol. 2011;40(6):1678-92. https://doi.org/10.1093/ije/dyr152. 
27. Torgerson DJ. Contamination in trials: is cluster randomisation the answer? BMJ. 2001;322(7282):355-7. https://doi.org/10.1136/bmj.322.7282.355.

28. Hayes RJ, Bennett $\mathrm{S}$. Simple sample size calculation for cluster randomized trials. Int J Epidemiol. 1999;28(2):319-26. https://doi.org/10.1093/ije/28.2.319.

29. Center for Disease Control and Prevention, Handwashing: clean hands save lives. Centers for Disease Control and Prevention, Atlanta, 2013: available at: https://www.cdc.gov/handwashing/index.html. Accessed 17 June 2017.

30. Guandalini S, Vaziri H. Diarrhea: diagnostic and therapeutic advances: Springer Science \& Business Media; 2010.

31. Morris SS, Cousens SN, Lanata CF, Kirkwood BR. Diarrhoea-defining the episode. Int J Epidemiol. 1994;23(3):617-23. https://doi.org/10.1093/ije/23.3.617.

32. Acharya, T., Membrane filter technique. Available at https://microbeonline. com/membrane-filter-technique/. Accessed 25 October 2020. 2010.

33. Wright J, Gundry S, Conroy R. Household drinking water in developing countries: a systematic review of microbiological contamination between source and point-of-use. Tropical Med Int Health. 2004;9(1):106-17. https:// doi.org/10.1046/j.1365-3156.2003.01160.x.

34. Liang K-Y, Zeger SL. Longitudinal data analysis using generalized linear models. Biometrika. 1986;73(1):13-22. https://doi.org/10.1093/biomet/73.1.13.

35. Odueyungbo A, Browne D, Akhtar-Danesh N, Thabane L. Comparison of generalized estimating equations and quadratic inference functions using data from the National Longitudinal Survey of Children and Youth (NLSCY) database. BMC Med Res Methodol. 2008;8(1):28. https://doi.org/10.1186/14 71-2288-8-28.

36. Shahid NS, Greenough WB III, Samadi AR, Huq MI, Rahman N. Hand washing with soap reduces diarrhoea and spread of bacterial pathogens in a Bangladesh village. J Diarrhoeal Dis Res. 1996;14(2):85-9.

37. Cairncross S, Hunt C, Boisson S, Bostoen K, Curtis V, Fung ICH, Schmidt WP. Water, sanitation and hygiene for the prevention of diarrhoea. Int J Epidemiol. 2010;39(suppl 1):i193-205. https://doi.org/10.1093/ije/dyq035.

38. Luby SP, Agboatwalla M, Feikin DR, Painter J, Billhimer W, Altaf A, Hoekstra RM. Effect of handwashing on child health: a randomised controlled trial. Lancet. 2005;366(9481):225-33. https://doi.org/10.1016/S0140-673 6(05)66912-7.

39. Luby SP, Agboatwalla M, Painter J, Altaf A, Billhimer W, Keswick B, Hoekstra RM. Combining drinking water treatment and hand washing for diarrhoea prevention, a cluster randomised controlled trial. Tropical Med Int Health. 2006;11(4):479-89. https://doi.org/10.1111/j.1365-3156.2006.01592.x.

40. Curtis V, Cairncross S. Effect of washing hands with soap on diarrhoea risk in the community: a systematic review. Lancet Infect Dis. 2003;3(5):275-81. https://doi.org/10.1016/S1473-3099(03)00606-6.

41. Aiello AE, Coulborn RM, Perez V, Larson EL. Effect of hand hygiene on infectious disease risk in the community setting: a meta-analysis. Am J Public Health. 2008:98(8):1372-81. https://doi.org/10.2105/AJPH.2007.124610.

42. Darvesh N, Das JK, Vaivada T, Gaffey MF, Rasanathan K, et al. Water, sanitation and hygiene interventions for acute childhood diarrhea: a systematic review to provide estimates for the Lives Saved Tool. BMC Public Health. 2017:17(4):776. https://doi.org/10.1186/s12889-017-4746-1.

43. Sircar B, Sengupta P, Mondal S, Gupta D, Saha N, et al. Effect of handwashing on the incidence of diarrhoea in a Calcutta slum. J Diarrhoeal Dis Res. 1987:112-4

44. Zomer T, Erasmus V, Looman C, Tjon-A-Tsien A, Van Beeck E, et al. A hand hygiene intervention to reduce infections in child daycare: a randomized controlled trial. Epidemiol Infect. 2015;143(12):2494-502. https://doi.org/10.1 017/S095026881400329X

45. Scott B, Curtis V, Rabie T. Protecting children from diarrhoea and acute respiratory infections: the role of handwashing promotion in water and sanitation programmes. In: WHO Reg Health Forum; 2003.

\section{Publisher's Note}

Springer Nature remains neutral with regard to jurisdictional claims in published maps and institutional affiliations.

Ready to submit your research? Choose BMC and benefit from:

- fast, convenient online submission

- thorough peer review by experienced researchers in your field

- rapid publication on acceptance

- support for research data, including large and complex data types

- gold Open Access which fosters wider collaboration and increased citations

- maximum visibility for your research: over $100 \mathrm{M}$ website views per year

At $\mathrm{BMC}$, research is always in progress.

Learn more biomedcentral.com/submissions 